\title{
Research on the Influence of Internet on Scientific and Technological Innovation Based on the Threshold Model of Financial Development
}

\author{
Tianzheng Luo ${ }^{1, *}$
}

${ }^{1}$ School of Government, Beijing Normal University, Beijing, China

*Corresponding author. Email: 154408301@qq.com

\begin{abstract}
Based on the panel data of 30 provinces (cities and autonomous regions) in China from 2008 to 2017, this paper establishes a threshold model to analyze the impact of Internet on scientific and technological innovation in regions with different levels of financial development, and explores the nonlinear transmission mechanism of Internet on scientific and technological innovation.
\end{abstract}

\section{Keywords: Internet, science and technology innovation, threshold model, financial development}

\section{INTRODUCTION}

With the rise of a new round of science and technology revolution in the world, driven by the wave of information technology, people have entered the digital economy era represented by new business forms such as the Internet, big data, cloud, sharing economy, and knowledge economy. The Internet is the main carrier of the digital economy. A series of actions contained in the digital economy are based on the Internet. It is promoting and changing technological innovation and economic development in all aspects. The Chinese government also attaches great importance to the development of the Internet and has proposed development strategies such as "Internet + " and "digital economy", it can be seen that promoting the development of the Internet has important practical significance for economic upgrading and technological progress. However, there's a reality problem currently in China that is unbalanced development in different region of China, so how Internet makes better to promote scientific and technological innovation in different regions is a topic to be exploring.

The main scholars who study the endogenous growth theory believe that the Internet can promote the occurrence of scientific and technological innovation process, while the adoption of new technologies can further accelerate economic growth (Lucas, 1988; Romer, 1990; Aghion and Howitt, 1998). On the one hand, the Internet can promote scientific and technological innovation by reducing transaction costs of enterprises and organizations (Benhabib and Spiegel, 2005). On the other hand, the Internet fundamentally changes the information processing mechanism, improves the efficiency of enterprise research and development, and thus guides innovation. In addition, the Internet can reduce the occurrence of information asymmetry and moral hazard and reduce the supervision cost of scientific and technological innovation (Myers, Majlu, 1984). There are also empirical studies that prove that the development of information and communication technologies such as the Internet has a positive effect on enterprise innovation (Wang Lina, Zhang Guoping, 2018). At the same time, some studies have found that financial development can promote scientific and technological innovation by reducing financing constraints (Carpenter, Petersen, 2002) and sharing innovation risks (Zhong Teng, 2019). Based on theoretical analysis, some scholars analyzed the data of Chinese listed companies from 2002 to 2006 and found that the development of regional financial industry can promote the innovation investment of enterprises (Xie Weimin, Fang Hongxing, 2011).

For the Internet and scientific and technological innovation, financial development and scientific and technological innovation, there have been relevant studies and discussions. However, in regions with different financial development levels, the development of the Internet may have different impacts on scientific and technological innovation. There is a lack of research and discussion on whether the development of the Internet from different aspects has the same impact on the output of scientific and technological innovation. Based on this, this paper uses financial development as a threshold variable to establish a threshold model, explores the impact of the Internet on technological innovation in regions with different levels of financial development, and analyzes and discusses the development trend of innovation gaps between regions. There are two innovations in this research. First, a threshold model is established to test whether there is a 
non-linear relationship between the Internet and technological innovation. Secondly, in the past, heterogeneity studies have mostly divided the relationship between the east, central, and western regions to analyze the differences in their relationships, and there is a lack of research on how the Internet promotes innovation from the perspective of finance.

\section{MODEL DESIGN AND VARIABLE} SELECTION

\section{A. Model settings}

Due to the differences in the level of financial development between regions in China, therefore, in

$$
Y_{i t}=b_{0}+b_{1} \text { Inter }_{i t} \cdot I\left(F D_{i t} \leq \gamma_{1}\right)+b_{2} \text { Inter }_{i t} \cdot I\left(\gamma_{1} \leq F D_{i t} \leq \gamma_{2}\right)+\ldots+b_{n} \text { Inter }_{i t} \cdot I\left(\gamma_{n-1} \leq F D_{i t} \leq \gamma_{n}\right)+b_{n+1} \text { Inter }_{i t} \cdot I
$$$$
\left(F D_{i t}>\gamma_{n}\right)+b_{c} X_{i t}+\lambda_{i}+e_{i t}
$$

Where, $y_{i t}$ indicates the technological innovation output of province $i$ in year $t$; Inter $_{i t}$ indicates the collective name of internet development-related indicators of province $i$ in year $t$, which will be brought into the Internet infrastructure level indicator int and Internet use level indicator web during model measurement. Estimated separately, $F D_{i t}$ represents financial development, using financial scale (fin) and financial efficiency (fineff), $X_{i t}$ is other control variables that may affect the performance of technological innovation, $\lambda_{i}$ represents non-observed individual fixed effects, and $\varepsilon_{i t}$ is a random perturbation term.

\section{B. Variable setting}

In this paper, the number of invention patent applications of industrial enterprises above the regional scale is used as the explained variable y to reflect the actual results of regional scientific and technological innovation output. Although some literature also uses the sales of new products as innovation performance in the stage of technological innovation transformation, considering that in the development of the Internet digital economy, new product sales include a certain percentage of sales of non-technological innovation products, so, this article only uses the number of invention patent applications that can directly reflect the output of scientific and technological innovation as the explanatory variables.

Internet development is the core explanatory variable considered in this article. Regarding the development of the Internet, considering that the development of the Internet is a comprehensive manifestation of various aspects, there is currently no official comprehensive index for Internet development published. Therefore, in this paper, the ratio of the number of registered websites in each province to the number of regional legal entities is used to measure the use of the Internet. And the number of Internet order to understand whether there is a non-linear relationship between Internet development and technological innovation output in regions with different levels of financial development, this article introduces two aspects: the level of Internet infrastructure and the level of use. As a representative of the level of Internet development, a threshold analysis framework for scientific and technological innovation output is established (Hansen, 1999). The model is as follows: broadband access ports in each province is used to measure the level of Internet infrastructure.

Financial development is a threshold variable. Considering that the development of the financial system is not only the expansion of the city scale, but also the improvement of efficiency, this article analyzes the relationship between financial development and the Internet and technological innovation from the perspective of financial scale and financial efficiency. Among them, the total financial assets of each province are used. (The sum of bank deposits and loans and the market value of the stock market) and GDP are used to reflect the financial scale (fin); at the same time, the DEA method was used to measure the efficiency of financial asset allocation (Yang Youcai et al., 2019), As a financial efficiency variable (fineff). In the DEA measurement, the input variables used include loan balances of provincial financial institutions, government fiscal expenditures, and number of financial employees; output variables are the value added of the financial industry in each province.

In addition, in order to better analyze the relationship between the Internet, finance and innovation, this paper controls the relevant variables. Among them, the "marketization index" ( $m k t)$ is used to indicate the marketization level of each province. The ratio of the province's technology market transactions to the province's GDP $(z s c q)$ is used to indicate the protection of intellectual property in the region. Use the full-time equivalent $(l)$ of R\&D personnel of industrial enterprises above designated size in each province to indicate the human capital investment in scientific and technological innovation in each region.

\section{Data sources}

The data in this article comes from the official website and the relevant yearbooks. The research samples are the provincial administrative regions in China. Excluding Hong Kong, Macao and Taiwan 
regions and the Tibet Autonomous Region, a total of 30 province sample data were collected. Considering the lack of data related to the early development of the Internet and the change in the statistical caliber of the science and technology yearbook, the research period was finally determined to be 2008-2017. All data in this article come from "China Statistical Yearbook", "China Industrial Statistical Yearbook", "Almanac of China's Finance and Banking", "China Statistical Yearbook on Science and Technology", "Marketization Index of China Province: NERI Report", the official website of China Internet Network Information Center Published statistical reports and website of the National Bureau of Statistics.

\section{EMPIRICAL RESULTS AND ANALYSIS}

In order to understand whether the role of the Internet in promoting technological innovation differs among provinces in the context of unbalanced financial development in China's provinces, this article uses a threshold model to conduct an empirical test of its specific impact. The existence of the threshold was tested first. Then through the inspection, it was found that the threshold of financial scale passed the single threshold test in the threshold test using the Internet use level as the core variable, and passed the threshold test using the Internet infrastructure level as the core variable. However, the regional financial efficiency threshold only passed the single threshold test in the threshold test of the two core variables. "Table I" shows the results of the threshold effect test. In this paper, existence tests are performed on single, double, and triple thresholds. Only the results of single and double tests are shown because the output are not significant for triple thresholds of all test models.

TABLE I. THRESHOLD EXISTENCE TEST

\begin{tabular}{llccccc}
\hline Threshold & F & $\mathbf{P}$ & $\begin{array}{c}\text { Threshold } \\
\text { Value }\end{array}$ & $\mathbf{F}$ & $\mathbf{P}$ & $\begin{array}{c}\text { Threshold } \\
\text { Value }\end{array}$ \\
\hline \multicolumn{7}{c}{ fin-web } \\
\hline I & $40.87^{* * * a}$ a & 0.000 & 1.173 & $49.85^{* * *}$ & 0.000 & 1.164 \\
\hline II & 3.69 & 0.606 & 0.970 & $10.80^{* *}$ & 0.043 & 1.545 \\
\hline & fineff-web & & & fineff-int & \\
\hline I & $14.21^{* *}$ & 0.023 & 0.197 & $16.83^{* *}$ & 0.010 & 0.197 \\
\hline II & 9.25 & 0.51 & 0.871 & 12.36 & 0.44 & 0.347 \\
\hline
\end{tabular}

a. a : ***,****indicate significant at $1 \%, 5 \%$, and $10 \%$ levels $; \mathrm{F}$ value, $\mathrm{p}$ value and threshold value are all obtained by repeated sampling of 300 times by the "self-help sampling method"

It can be seen from "Table I" that, for the level of Internet use, the threshold value of financial scale is 1.173, which divides the financial scale of each province into two ranges: low scale below 1.173 and high scale above 1.173. For the level of Internet infrastructure construction, there are two thresholds of financial scale: 1.164 and 1.545, namely the low scale below 1.164, the medium scale between 1.164 and 1.545 , and the high scale above 1.545 . There is only a significant single threshold for financial efficiency in terms of Internet usage level and Internet infrastructure level, and the threshold value is 0.197 after retaining three decimal places. Comparing the threshold values of Internet usage level and Internet infrastructure level in "Table I", it can be found that the threshold values of single weight are close to each other. That means, for different Internet development variables, similar threshold values of financial development are obtained. Therefore, it can indirectly reflect that the two variables of Internet usage level and Internet infrastructure level have certain representative significance for the development of Internet. 
TABLE II. THE THRESHOLD MODEL ESTIMATES THE RESULT

\begin{tabular}{|c|c|c|c|c|}
\hline \multirow{2}{*}{ Variables } & \multicolumn{2}{|c|}{ fin } & \multicolumn{2}{|c|}{ fineff } \\
\hline & (1) & (2) & (3) & (4) \\
\hline \multirow[t]{2}{*}{ fin } & $0.029^{* * a}$ & 0.016 & $0.043^{* * *}$ & $0.049^{* * * *}$ \\
\hline & (2.19) & $(1.21)$ & $(3.22)$ & (3.81) \\
\hline \multirow[t]{2}{*}{ fineff } & $0.417^{* *}$ & 0.253 & $0.581^{\text {**** }}$ & $0.663^{* * *}$ \\
\hline & $(2.35)$ & $(1.45)$ & $(0.002)$ & $(3.90)$ \\
\hline \multirow[t]{2}{*}{$m k t$} & $0.063^{* *}$ & $0.096^{* * *}$ & $0.083^{* * *}$ & $0.100^{* * * *}$ \\
\hline & $(2.42)$ & (3.89) & $(0.003)$ & (3.77) \\
\hline \multirow[t]{2}{*}{$z s c q$} & -0.552 & 1.833 & -0.824 & 0.125 \\
\hline & $(-0.42)$ & (1.52) & $(-0.59)$ & (0.10) \\
\hline \multirow[t]{2}{*}{$l$} & $0.890^{* * * *}$ & $0.739^{* * * *}$ & $0.835^{\text {*** }}$ & $0.720^{* * * *}$ \\
\hline & $(30.22)$ & (15.39) & $(27.86)$ & (13.97) \\
\hline \multirow[t]{2}{*}{$w e b \_1$} & $-1.771^{* * * *}$ & & $-2.137^{* * * *}$ & \\
\hline & $(-4.87)$ & & $(-3.33)$ & \\
\hline \multirow[t]{2}{*}{$w e b \_2$} & $0.424^{* * *}$ & & $0.296^{* *}$ & \\
\hline & $(2.22)$ & & $(2.50)$ & \\
\hline \multirow[t]{2}{*}{ int_1 } & & $0.194^{* * *}$ & & 0.104 \\
\hline & & $(3.23)$ & & (1.53) \\
\hline \multirow[t]{2}{*}{ int_2 } & & $0.256^{* * * *}$ & & $0.175^{* * *}$ \\
\hline & & $(4.28)$ & & $(2.72)$ \\
\hline \multirow[t]{2}{*}{ Int_3 } & & $0.285^{* * *}$ & & \\
\hline & & $(4.65)$ & & \\
\hline \multirow[t]{2}{*}{ cons } & $-2.267^{* * *}$ & $-2.535^{* * *}$ & $-1.945^{* * *}$ & $-2.01^{* * *}$ \\
\hline & $(-10.93)$ & $(-12.41)$ & $(-8.96)$ & $(-9.42)$ \\
\hline A-R2 & 0.906 & 0.935 & 0.900 & 0.925 \\
\hline $\mathrm{N}$ & 300 & 300 & 300 & 300 \\
\hline
\end{tabular}

"Table II" shows the estimated results of two types of thresholds: financial scale and financial efficiency. According to model (1), under the single threshold of financial scale, the increase in the level of Internet use has different effects on the technological innovation output in the two areas. In low-scale provinces, an increase in the use of the Internet has a significantly negative correlation to the output of technological innovation, while in high-scale provinces, an increase in the use of the Internet has a significantly positive correlation to the output of science and technology. In other words, in regions with lower financial scale, the higher the rate of use of the Internet by enterprises, the lower the level of output of technological innovation; in regions with higher financial scale, the higher the rate of use of the Internet by enterprises, the output of technological innovation is greater in the higher the region. This situation may be due to the relatively low level of regional economic development in provinces with smaller financial scales, the tendency of enterprises to increase sales is greater than the tendency of innovative research and development, and the use of the Internet is more used to facilitate the sales of products. Therefore, the higher the level of Internet use, it may make companies pay more attention to product sales and ignore innovation research and development, which indirectly inhibits the output of technological innovation. From model (2), it can be seen that the coefficient of Internet infrastructure level in each interval under the double threshold is significantly positive, indicating that there is a non-linear positive effect between the Internet infrastructure level and the province's scientific and technological innovation output. Specifically, in the low-scale range, the estimated coefficient of the Internet infrastructure level is 0.194 , and in the medium-scale range, the coefficient rises to 0.256 , which means that the improvement of the Internet infrastructure level has increased the promotion of scientific and technological innovation output. In the range of scale, this driving effect is further enhanced, and the estimated coefficient reaches 0.285 . It can be seen that the level of Internet infrastructure promotes the "increasing marginal benefits" of technological innovation output. Furthermore, this driving effect has widened the gap in technological innovation output between provinces with different financial scales. With the strengthening of the Internet infrastructure, if the imbalance in financial development between provinces cannot be improved, a technological divide may occur. Therefore, promoting financial development is also one of the key factors that cannot be ignored in improving the regional innovation capacity.

Model (3) and model (4) are the financial efficiency threshold estimation results. By model (3), in a single threshold under heavy financial efficiency and level of Internet use for regional scientific and technological innovation output shows the opposite effect, in the low efficiency of provinces, both were significantly 
negative correlation, and in the provinces with high efficiency, the estimated coefficients are significant, the result is similar to financial scale threshold estimation results, the reasons for this result may be linked to causes of the financial scale threshold model estimation results. In addition, low financial efficiency also means that the allocation and transformation efficiency of financial resources in this region is insufficient, which may result in the failure of timely delivery of innovation funds, thus inhibiting scientific and technological innovation. And these outputs show that in addition to financial scale, too low financial efficiency will also have a negative impact on the Internet's promotion of technological innovation. In model (4), the estimated coefficient of Internet infrastructure level in the low range is not significant, but the positive coefficient also reflects the region in the range to some extent, and the level of Internet infrastructure promotes the improvement of scientific and technological innovation production. In the high efficiency range, the level of Internet infrastructure is positively correlated with the output of scientific and technological innovation. Comparing the two interval coefficients, it can be found that the Internet infrastructure level plays a greater role in promoting scientific and technological innovation in the high efficiency interval than the low efficiency interval. Although the financial efficiency threshold of model (4) and model (2) is different, the estimated results of the two models both find that the development of the Internet can promote the output of scientific and technological innovation, but the impact is different in different financial efficiency regions. In addition, due to the existence of financial efficiency threshold, the continuous development of the Internet will widen the gap of scientific and technological innovation ability among some provinces. In other words, although financial efficiency will not weaken the spillover effect of the Internet on innovation, it will indirectly aggravate the imbalance of scientific and technological innovation output in different regions of China.

\section{CONCLUSION}

This paper uses 30 provinces in China as a research sample, and establishes a threshold model with financial development as the threshold variable. It explores the non-linear mechanism of the Internet to promote technological innovation and concludes that: The Internet can promote scientific and technological innovation through the development of financial scale and financial efficiency. The level of Internet use has a certain inhibitory effect on the output of scientific and technological innovation in regions with low financial scale or financial efficiency, while it has a significant promoting effect on the output of scientific and technological innovation in regions with high financial scale or financial efficiency. The improvement of the level of Internet infrastructure plays a significant positive role in the output of scientific and technological innovation in regions with different financial scale and financial efficiency, but the promotion of scientific and technological innovation in regions with low financial scale or financial efficiency is small, and the promotion of scientific and technological innovation in regions with high financial scale or financial efficiency is large. Therefore, although the Internet improves the output of scientific and technological innovation on the whole, it also widens the gap of innovation capacity between regions with different levels of financial development.

\section{References}

[1] Aghion, Philippe. Howitt, et al. Endogenous Growth Theory. MIT Press. 1998

[2] Benhabib, J. \& Spiegel, M.. The Role of Financial Development in Growth and Investment [J]. Journal of Economic Growth, 2000, 5(4), pp.341-360.

[3] Carpenter, R.E.. Petersen, B.C.. Capital Market Imperfections, High-tech Investment, and New Equity Financing. Economic Journal, 2002, 112(477), pp. F54-F72.

[4] Hansen B E. Threshold effects in non-dynamic panels: Estimation, testing, and inference[J]. Journal of Econometrics, 1999, 93(2), pp. 345-368.

[5] Lucas. Robert E. On the mechanics of economic development [J]. Journal of Monetary Economics, 1998, 22(1), pp. 3-42.

[6] Myers, Stewart C. Majluf, Nicholas S.Corporate financing and investment decisions when firms have information that investors do not have. Journal of financial economics., 1984, 13(2), pp. 187-221.

[7] Romer, Paul Michael. Endogenous Technological Change [J] Journal of Political Economy, 1990, 98(5), pp. 71-102.

[8] Xie Weimin, Fang Hongxing. Financial development, Financing constraints and enterprise $\mathrm{R} \& \mathrm{D}$ investment $[\mathrm{J}]$. Journal of Financial Research, 2011(5), pp. 171-183.

[9] Wang Lina, Zhang Guoping. Information Technology, Human Capital and Innovation of Start-up Firms:An Empirical Study Based on Enterprise-Level Data of China[J]. Science of Science and Management of S.\&T., 2018, 39(04), pp. 111-222.

[10] Yang Youcai, Wang Xi, et al. Evolution of Allocation Efficiency of Financial Resource, TFP growth and China's Economy Development - Based on Panel Data PVAR Model[J]. Management Review, 2019, 31(06), pp. 36-48. 